\title{
Numerical and experimental study of the fatigue of threaded pipe couplings
}

\author{
J. Van Wittenberghe, P. De Baets, W. De Waele \& S. Van Autrève \\ Laboratory Soete, Faculty of Engineering Ghent University, Belgium
}

\begin{abstract}
Threaded pipe couplings are used in the oil and gas industry as an alternative to welding and in applications where pipes should be frequently coupled and uncoupled as is the case for drill pipes. To maintain a sealed and secure connection while being subjected to external variable loads, they are commonly preloaded by using threaded connections with a conical shape. In this study a series of finite element analyses of conical threaded API Line Pipe couplings is carried out to quantify the influence of its contact parameters (coefficient of friction, preload and taper angle). In the assembled pipes, small sliding of the thread contact surfaces is still possible due to elastic deformation under external loads. This means that the contact zones of the threads can change under load, which complicates the analysis of the couplings. It was found that the coefficient of friction between the threads had a significant influence on this sliding. The shape of the threads inherently causes local stress concentrations, which can in turn initiate fatigue cracks. To validate the results of the finite element simulations, both static and dynamic tests were carried out on an API Line Pipe coupling. The preloading of the connection was carried out on a torque machine and an experimental fatigue test was carried out on a four-point bending test setup. Strains measured by strain gauges on the connections are in good agreement with the strains predicted by the finite element simulations. Fatigue cracks appearing emanated from the root of the last engaged thread of the male part of the connection, which is the region with the highest stress concentration factor in the numerical model.
\end{abstract}

Keywords: threaded connection, pipe coupling, finite element analysis, coefficient of friction, experimental testing. 


\section{Introduction}

Threaded pipe couplings are commonly used in the oil and gas industry as an easy-to-assemble alternative for welding e.g. in risers and in applications where pipes should be frequently coupled and uncoupled as is the case for drill pipes. They consist of a male and a female part called respectively 'pin' and 'box'. Fatigue failure of threaded pipe couplings is an important problem. Although much research has been done in this field, its frequency of occurrence is still excessive. In the case of drill strings, it was reported by Vaisberg et al. [1] that up to $73 \%$ of all drill string defects were caused by fatigue cracks. Fatigue failure is caused by cyclic loads that appear in drill strings during drilling operations. Risers are underwater pipelines that connect oil wells in the seabed to oil rigs. They are subjected to cyclic loads by displacement of the rig, waves, tides and currents, which can induce vibrations in the riser.

It is essential for the couplings, first of all, to maintain a secure connection between the different pipes of the pipeline or string, which does not loosen under the influence of external loads and vibrations. Secondly, they should provide a good sealing to prevent the coupling from leaking. To achieve this, the connections commonly have a conical shape that enables them to be preloaded. This preload is attained by applying a certain torque to the coupling. The torque value is different for every connection type and size and is commonly referred to as the 'make-up torque'. The combination of the make-up torque together with external loads and the geometry of the threads results in a complex stress distribution over the connection. Local stress concentrations at the thread roots can initiate fatigue cracks, in time causing the connection to fail. According to Griffin et al. [2], the highest stress concentration under axial load can be expected at the last engaged thread (LET) of the pin. Newport and Glinka [3] showed that this is because the load is distributed unevenly over the threads of the connection and the thread carrying the highest load is the LET of the pin. In order to improve the fatigue strength of a threaded connection, these stress concentrations and the load distribution over the threads should be studied.

Both global and local connection parameters can have an influence on the load and stress distribution over the connection. It is known from Newport and Glinka [3] that the thread type has an influence on the stress concentration factor in the root of the threads since a thread acts like a notch and has a stress raising effect on the local stress. Assanelli et al. [4] showed that the load distribution over the threads can be changed by altering the taper angle of the pin or box, creating a small mismatch.

Despite the make-up torque, small sliding of the thread contact surfaces is still possible due to elastic deformation under external loads. This means, the contact zones of the threads will change under load, which complicates the analysis of the couplings. In the present study it was found that the contact behaviour of the mating surfaces of the connection, and in particular the coefficient of friction (COF), has a significant influence on this sliding. A series of finite element analyses was carried out on a model of an API Line Pipe connection to quantify the influence of the coefficient of friction, the number of 
make-up turns and the taper angle. To validate the presented results make-up and fatigue tests were carried out.

\section{Finite element modelling}

\subsection{General practice}

It is general practice to model threaded connections using 2D axisymmetric models, as can be seen in [2] and [4-6]. The advantage of this approach is the reduced calculation time compared to full $3 \mathrm{D}$ models. In addition to this, due to their complexity, full 3D models have a tendency to be more unstable and to diverge from a stable solution more easily. The disadvantage of the 2D axisymmetric models is that they neglect the helical shape of the threads and the runout region. However, it was shown by Chen and Shih [7] in the analysis of bolts and later by Zhong [8] for threaded pipe connections, that the results of 2D axisymmetric models are in good agreement with the results of full 3D models.

There is a general consensus on using elastic-plastic material models since local stresses exceed the material's yield strength even in the make-up stage. For the coefficient of friction, however, very different values are used. Bahai et al. [9] assumed frictionless sliding. ISO 10407-1 [10] gives a coefficient of friction between 0.06 and 0.14 , mentioning a typical value of 0.08 when thread compounds are used. Recently Santus et al. [11] measured a value of 0.15 for a drill pipe joint even when thread compound was applied. As will be shown further, this variation of the COF has a significant influence on the performance of the connection. Since the coefficient of friction depends on the surface conditions of the threads and the thread compounds used, special attention has to be paid when choosing a value for the COF in a finite element model.

\subsection{API line pipe model}

In the present study 2D axisymmetric finite element analyses (FEA) were carried out using the software package ABAQUS ${ }^{\circledR}$. The model consists of an API Line Pipe threaded connection with a nominal size of 4" according to API 5B [12]. The pipe body has an outside diameter of $114.3 \mathrm{~mm}$ and wall thickness of $6 \mathrm{~mm}$, the box has a length of $114.3 \mathrm{~mm}$ and an outside diameter $132.1 \mathrm{~mm}$. An elasticplastic material model for API Grade B steel is used, which has a minimum yield strength of $241 \mathrm{MPa}$ and minimum tensile strength of $413 \mathrm{MPa}$ according to the API 5L specifications [13]. In the elastic region a Young's modulus of $208 \mathrm{GPa}$ and Poisson coefficient of 0.3 is used.

Part of the model of the API Line Pipe connection is shown in Figure 1. The model consists of a section of the pin and a section of a half box. The body of the pin extends over a length of $100 \mathrm{~mm}$ to the left to exclude boundary effects (not shown in the figure). Figure 1 also shows the resulting von Mises stresses from an analysis of the standard API Line Pipe connection. The analysis is done in two steps. 


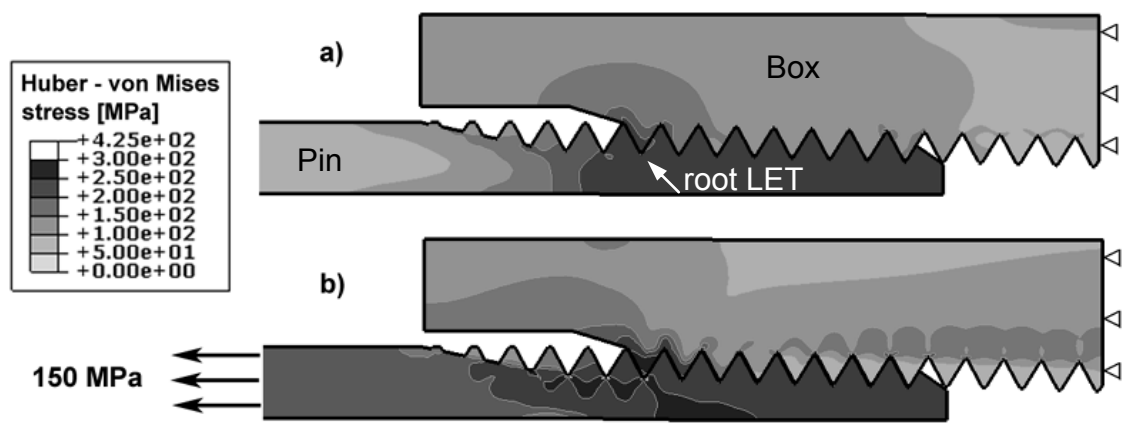

Figure 1: Von Mises stress distribution for a standard 4" API Line Pipe connection: a) at make-up; b) with an additional external tensile stress of $150 \mathrm{Mpa}$.

During the first step, the make-up is modelled by applying an initial overlap between the male and female part of the connection and then bringing them into contact. The size of the overlap corresponds to the specified number of make-up turns. In the pin the make-up causes a compressive hoop stress which can be very high and even exceed the material's yield strength.

Once the make-up step is completed, an additional external axial tensile stress is applied at the left end of the pin. The pull-out strength of this type of connection is $373 \mathrm{kN}$ (Clinedinst [14]), which corresponds with a uniform axial tensile stress of $183 \mathrm{MPa}$ in the pipe body. Since the modelling of thread pull-out is not of interest and does not correspond to a service condition, a maximum applied tensile stress of $150 \mathrm{MPa}$ was chosen.

As can be seen in Figure 1 the highest stress appears in the LET of the pin as can be expected from Griffin et al. [2]. This will also be the region where a fatigue crack is most likely to initiate.

\subsubsection{Coefficient of friction}

Once a certain external tensile stress is exceeded, the threads will start to slide over each other creating an opening between the threads. This means the gas or liquid inside the pipes will find their way out through the helical path created by the thread opening. It is obvious that such a leak is undesirable. From Figure 2 it can be seen that the opening is highly dependent on the coefficient of friction $\mu$ between the threads. The opening is defined as the perpendicular distance between the thread flanks, and varies between $0.03 \mathrm{~mm}$ when $\mu=0.16$ and $0.41 \mathrm{~mm}$ for the frictionless situation, at an external tensile stress of $150 \mathrm{MPa}$. The opening increases slowly from 0 to a value of approximately $0.025 \mathrm{~mm}$, and when a certain limit stress $S_{L}$ is reached, the threads start to slide and the opening increases significantly. It can be seen from the graph that the limit stress increases with increasing COF and that paths of the opening during sliding are parallel for the different COF's.

Based on the simulations, an empirical correlation was found for the limit stress $\mathrm{S}_{\mathrm{L}}$ and the opening $\mathrm{O}$ : 


$$
\begin{gathered}
\mathrm{S}_{\mathrm{L}}=124+\mu \cdot 169[\mathrm{MPa}] \\
\mathrm{O}=0.014\left(\mathrm{~S}-\mathrm{S}_{\mathrm{L}}\right)+0.025[\mathrm{~mm}] \text { for } \mathrm{S}>\mathrm{S}_{\mathrm{L}}
\end{gathered}
$$

With $\mathrm{S}$ the externally applied tensile stress in the pin body.

If during fatigue loading, the maximum cyclic stress exceeds the limit stress, there is a possibility for fretting fatigue cracks to initiate from the threads contact surface.

\subsubsection{Load distribution over the threads}

When the threads start to slide, the contacting surfaces of the threads will decrease, increasing the resulting contact pressure. The load distribution over the threads, however, is not affected by this pressure change and is the same for the different COF's. The load distributions for an external tensile stress of $100 \mathrm{MPa}$ and $150 \mathrm{MPa}$ as a percentage of the total load is given in Figure 3. Thread nr. 1 corresponds to the LET of the pin.

Note that at an external stress of $100 \mathrm{MPa}$ the LET carries $47 \%$ of the total load. With a higher external stress applied, the LET will start to bend, transmitting part of its load to the other threads. This way the tooth load decreases to $36 \%$ at a tensile stress of $150 \mathrm{MPa}$.

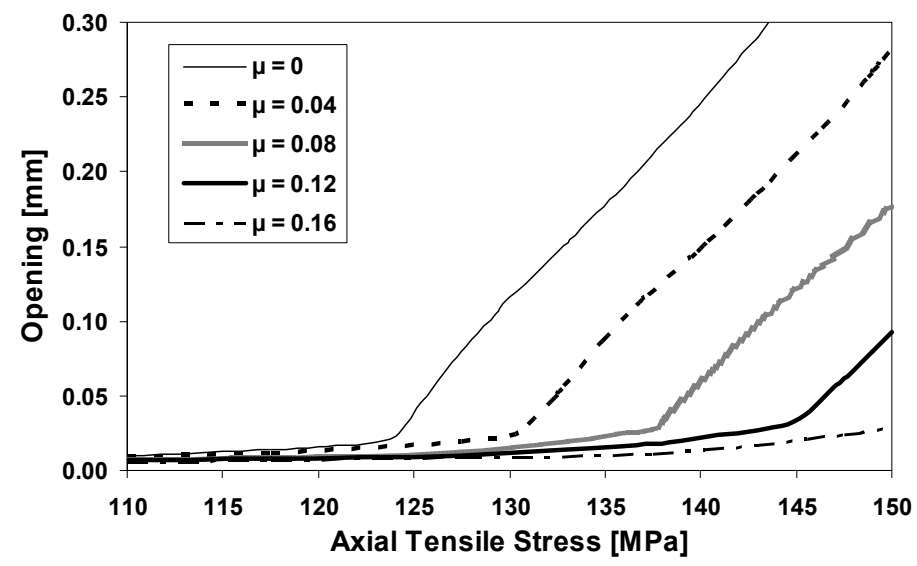

Figure 2: Influence of the coefficient of friction on the thread opening.

\subsubsection{Number of make-up turns}

According to the API 5B specifications [12], the connection should be made up in such a way that the end of the box recess (unthreaded part at the left side of the box in Figure 1) coincides with the plane of the vanishing point of the thread runout of the pin. Depending on the tolerances this should correspond with between 1 and 3 make-up turns. As will be shown in paragraph 3.1.2 the number of make-up turns to be used in the models should be lower than the specified number since a certain rotation is necessary to settle the connection. For this reason the number of make-up turns was varied from 0.25 to 3 (see Figure 4). The tooth load at the LET of the pin with an external stress of $150 \mathrm{MPa}$ does not 
change significantly with the number of make-up turns. For an external tensile stress of $100 \mathrm{MPa}$, the tooth load at the LET of the pin increases linearly from $47 \%$ to $53 \%$ for 1 to 3 make-up turns, but for a lower number of make-up turns the tooth load moves to the values obtained for the higher stress of $150 \mathrm{MPa}$. The thread opening decreases with increasing number of make-up turns, but saturates for 1.75 make-up turns or more. This is because the engaged body of the pin yields completely and plastic deformation appears for 1.75 make-up turns or more.

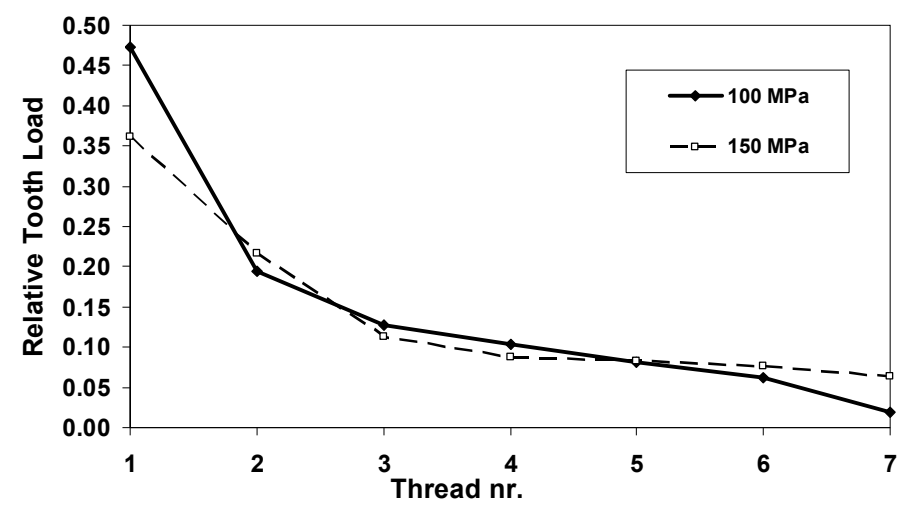

Figure 3: Load distribution over the threads as a percentage of the total load.

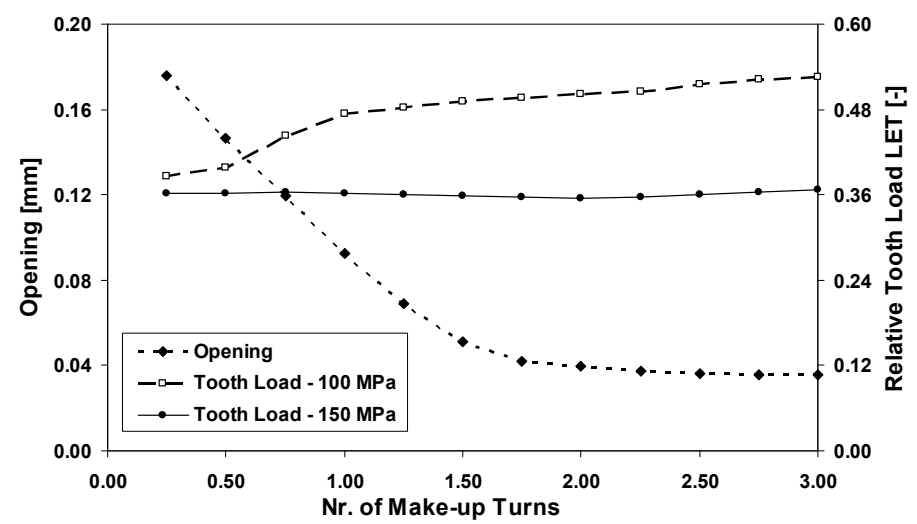

Figure 4: Influence of make-up turns on thread opening and relative tooth load on the LET of the pin $(\mu=0.12)$.

\subsubsection{Taper angle}

The taper angle of both pin and box of the API Line Pipe connection has a nominal value of $3.576^{\circ}$ and can be maximum $3.873^{\circ}$ or minimum $3.428^{\circ}$. By changing the taper of both pin and box between these tolerances, it was found 
that the taper difference $\Delta \mathrm{t}$ is the defining parameter for the behaviour of the connection. Where:

$$
\Delta \mathrm{t}=\operatorname{taper}_{\text {box }}-\operatorname{taper}_{\text {pin }}\left[{ }^{\circ}\right]
$$

It can be seen in Figure 5 that both tooth load at the LET of the pin and thread opening decrease with increasing taper difference, however, the influence of the taper difference is much smaller than the influence of the number of make-up turns.

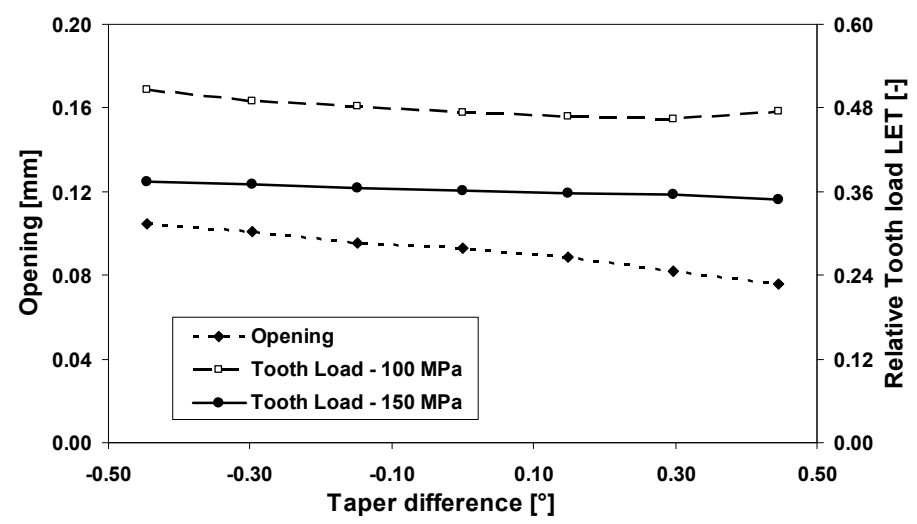

Figure 5: Influence of taper angle on thread opening and relative tooth load on the LET of the pin $(\mu=0.12$, number of make-up turns $=1)$.

\section{Experimental validation}

To validate the results of the finite element simulations two different types of tests were carried out on standard 4" API Line Pipe connections. To validate the modelling of the make-up and to obtain a value for the COF between the threads the make-up of the connection was performed on a torque machine. A fatigue test was carried out on a four-point bending fatigue test setup using a coupled pipeline segment with a total length of $3 \mathrm{~m}$.

\subsection{Make-up tests}

\subsubsection{Torque machine description}

During the make-up it is necessary to accurately control the rotation and to measure the resulting torque. In order to do this, a setup was made by modifying an old torque machine. The new setup is presented in Figure 6a. The test specimen (1), consisting of a pin and box, is mounted in the torque machine by the use of flanges that are welded to pin and box. Drive wheel (2) rotates a worm which drives the gear (3). This causes the pin of the test specimen (1) to rotate with respect to the stationary box. The resulting torque is transmitted to the lever arm (5) which is connected to the loadcell (4). The measured load multiplied by the length of the lever arm $(1.00 \mathrm{~m})$ equals the acting torque. To allow an axial motion during make-up, a linear guiding system (6) is present. The torque 
machine has a capacity of $2500 \mathrm{Nm}$, and the maximum test specimen length is $400 \mathrm{~mm}$.

\subsubsection{Determination of the coefficient of friction}

Two torque tests were performed; the resulting torque-turn graph of one of the tests is shown in Figure 7. The number of rotations was put to zero at the point where the torque started to increase, the so-called 'hand-tight' situation. The total number of make-up turns is 1.09 , which lies within the area of the specified 1 to 3 make-up turns (see paragraph 2.2.3).

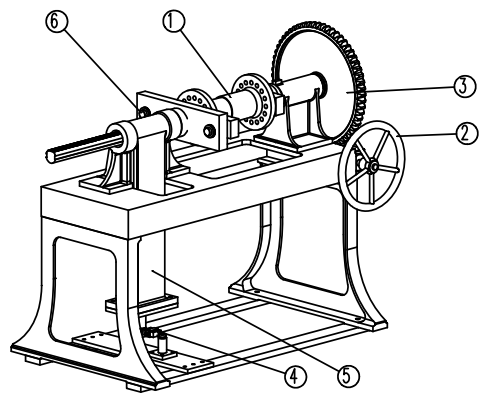

a)

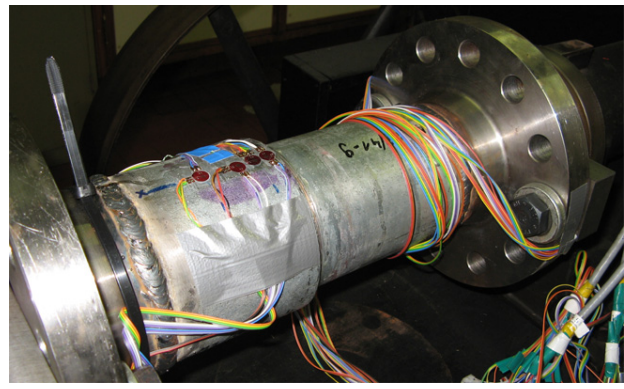

b)

Figure 6: a) Schematic view of the torque machine; b) instrumented test specimen mounted in the setup.

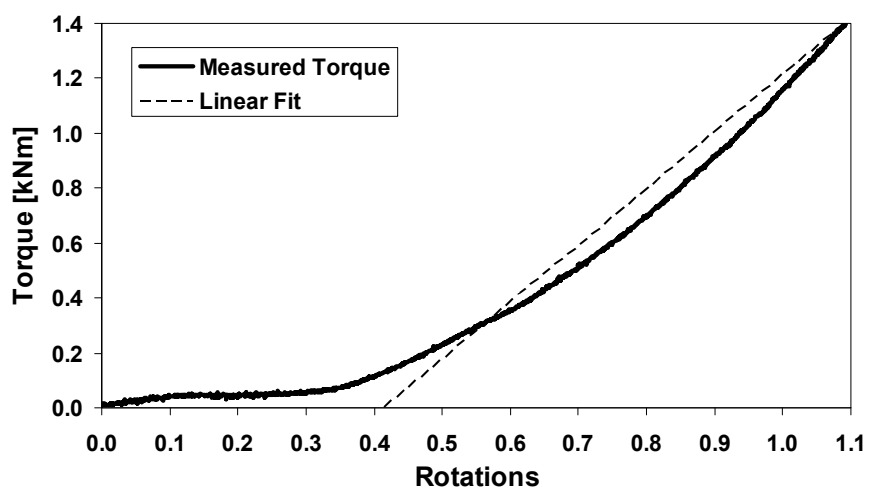

Figure 7: $\quad$ Torque vs. number of turns.

The measured make-up torque was $1401 \mathrm{Nm}$, which conforms API 5 C3 [15], that specifies the make-up torque should be between $850 \mathrm{Nm}$ and $1430 \mathrm{Nm}$. From the torque-turn data, a coefficient of friction can be calculated. This is done by finding the best linear fit that coincides with the final value of make-up torque and number of rotations. From the slope of this line, the COF can be calculated. For the two torque tests a value of $\mu=0.11$ and $\mu=0.15$ was found. 
As can be seen in Figure 7, the torque increases first to a value of about 50 $\mathrm{Nm}$ and stays constant for about 0.35 rotations. This is because all connections have some geometrical deviations and the connection needs to settle before the threads of pin and box are completely in contact with each other. Once the threads are fully contacting, the torque builds up, following the path of the linear fit. The linear fit becomes zero at a value of 0.42 rotations, so from this point of view, the number of final make-up turns is only $1.09-0.42=0.67$. This shifted value should be used as input for the finite element models since there is a perfect match between the geometry of pin and box in the models. In a previous study of Assanelli et al. [4] an analogue shift was observed for an API 8-round threaded connection.

\subsubsection{Strain measurements during make-up}

As can be seen in Figure $6 \mathrm{~b}$ strain gauges were attached to the test specimens to measure strains during make-up. They were attached at different locations over the outside wall of the box and the inside wall of the pin. The measured strain values at the final torque of $1401 \mathrm{Nm}$ were compared to the modelled strains. As input for the finite element model, a COF of $0.13,0.67$ make-up turns and the measured value for the taper difference was used.

The results are shown in Figure 8 for axial strain Exx and in Figure 9 for hoop strain Ezz. The distance is measured along the pipe axis, starting from the vanishing point of the thread runout of the pin. The RMS deviation between the measured and simulated values was $117 \mu \varepsilon$. When the number of make-up turns was changed to 0.60 , the RMS deviation even decreased to $80 \mu \varepsilon$. This situation would correspond to an experimental number of make-up turns of 1.02 and a torque of $1200 \mathrm{Nm}$. These values are still within the API specifications.

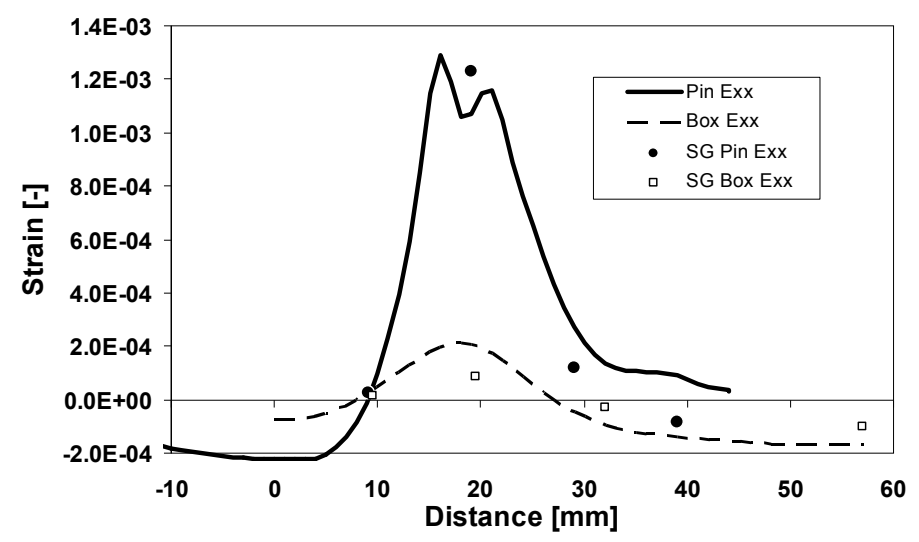

Figure 8: Axial strain Exx: calculated (lines) vs. measured by strain gauges SG (points).

\subsection{Fatigue test}

On a four-point bending setup, a fatigue test was carried out on coupled pipeline segments with a 4" API Line Pipe connection and a total length of $3 \mathrm{~m}$. The 
applied stress amplitude at the outside wall of the pin was $75 \mathrm{MPa}$ with an Rfactor of $0.1\left(\sigma_{\max }=167 \mathrm{MPa}, \sigma_{\min }=17 \mathrm{MPa}\right)$ and was fluctuated at a frequency of $1 \mathrm{~Hz}$. From the analysis of the measured data it was found that a crack started to grow from the last engaged thread of the pin (indicated by the arrow in Figure 10a) after 18620 cycles.

At 20350 cycles, the test was stopped and the connection uncoupled. The grease that was used during assembly had turned black, which is an indication of fretting corrosion.

Fretting corrosion could be expected since the maximum applied stress of $167 \mathrm{MPa}$ exceeds the limit stress $\mathrm{S}_{\mathrm{L}}=146 \mathrm{MPa}$ which is found by substituting the value of $\mu=0.13$ in equation (1).

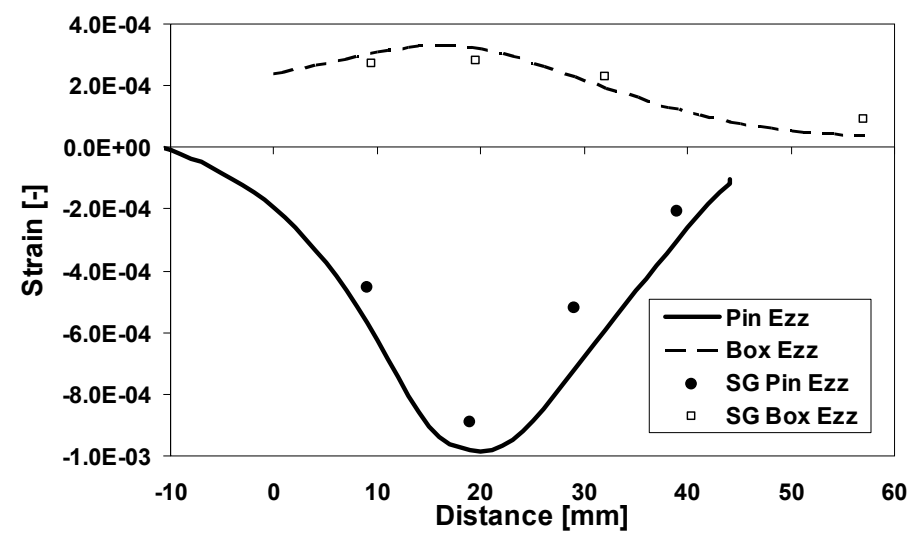

Figure 9: Hoop strain Ezz: calculated (lines) vs. measured by strain gauges SG (points).
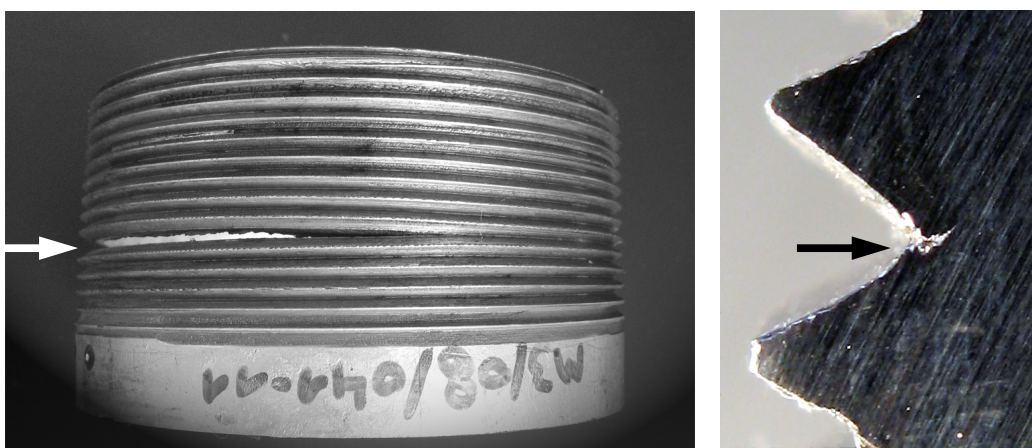

a)

b)

Figure 10: a) Fatigue crack emanating from LET pin; b) detail of the root of the LET of the pin. 
Detailed examination of the fracture surface showed that the crack initiated in the root of the LET of the pin (see detail in Figure 10b), which is the location with the highest stress concentration in the finite element model.

\section{Conclusions}

A 2D axisymmetric finite element model of an API Line Pipe threaded connection has been. It was used to simulate and analyse the behaviour of this coupling type. Complementary experimental tests have been carried out as a validation. Following conclusions can be made:

- Small sliding of the thread contact surfaces appears under external loads, the magnitude of this sliding depends significantly on the coefficient of friction and the number of make-up turns. Under fatigue loads, this sliding can cause fretting fatigue.

- A value for the coefficient of friction was determined based on torque measurements. Strains measured during the make-up tests were in good agreement with the values obtained with the model.

- The number of make-up turns given in the API specifications should not be used as such for input in finite element models.

- During the fatigue test a crack emanated from the root of the LET of the pin, which is the region with the highest stress in the finite element model.

\section{Acknowledgement}

The authors would like to acknowledge the financial support of the BOF fund $(\mathrm{B} / 04939)$ of the Ghent University-UGent and of the FWO Vlaanderen (3G022806).

\section{References}

[1] Vaisberg, O., Vincké, O., Perrin, G., Sarda, J.P. \& Faÿ, J.B., Fatigue of Drillstring: State of the Art. Oil \& Gas Science and Technology-Rev. IFP, 57(1), pp. 7-37, 2002.

[2] Griffin, R.C., Kamruzzaman, S., Strickler, R.D., Casing Drilling Drill Collars Eliminate Downhole Failures. Offshore Technology Conference, Houston, Texas, USA, 3-6 May 2004.

[3] Newport, A., Glinka, G., Concentration of Cyclic Stresses in Preloaded Threaded Connections. Journal of Engineering Mechanics-ASCE, 117(6), pp. 1257-1273, 1991.

[4] Assanelli, A.P., Xu, Q., Benedetto, F., Johnson, D.H., Dvorkin, E.N., Numerical/experimental analysis of an API 8-round connection. Journal of Energy Resources Technology-Transactions of the ASME. 119(2), pp. 8188, 1997.

[5] Dvorkin, E.N., Toscano, R.G., Finite element models in the steel industry, Part II: Analyses of tubular products performance. Computers \& Structures, 81(8-11), pp. 575-594, 2003. 
[6] Guangjie, Y., Zhenqiang, Y., Qinghua, W., Zhentong, T., Numerical and experimental distribution of temperature and stress fields in API round threaded connection. Engineering Failure Analysis, 13(8), pp. 1275-1284, 2006.

[7] Chen, J.J., Shih, Y.S., A study of the helical effect on the thread connection by three dimensional finite element analysis. Nuclear Engineering and Design, 191(2), pp. 109-116, 1999.

[8] Zhong, A., Thread Connection Response to Critical Pressures, Abaqus Users' Conference, pp. 690-706, Paris, France, May 2007.

[9] Bahai, H., Glinka, G., Esat, I.I., Numerical and experimental evaluation of SIF for threaded connectors. Engineering Fracture Mechanics, 54(6), pp. 835-845, 1996.

[10] ISO 10407-1, Petroleum and natural gas industries - Drilling and production equipment - Part 1: Drill stem design and operating limits, 2004.

[11] Santus, C., Bertini, L., Beghini, M., Merlo, A., Baryshnikov, A., Torsional strength comparison between two assembling techniques for aluminium drill pipe to steel tool joint connection. International Journal of Pressure Vessels and Piping, doi:10.1016/j.ijpvp.2008.09.007, 2008.

[12] API Specification 5B, Specification for Threading, Gauging and Thread Inspection of Casing, Tubing and Line Pipe Threads (U.S. Customary Units), American Petroleum Institute, fourteenth edition, 1996.

[13] API Specification 5L, Specification for Line Pipe, American Petroleum Institute, forty-second edition, 2000.

[14] Clinedinst, W.O., Joint Strength Formulas for API Threaded Line Pipe, API Circular PS-1533, 1976.

[15] API Bulletin 5C3, Bulletin on Formulas and Calculations for Casing, Tubing, Drill Pipe and Line Pipe Properties, American Petroleum Institute, fifth edition, 1989. 